\title{
GESTIÓN PATRIMONIAL Y HÁBITAT: EL CASO DE LA COOPERACIÓN ESPAÑOLA EN EL CENTRO HISTÓRICO DE CUSCO [1999-2010] ${ }^{*]}$
}

\author{
PATRIMONIAL MANAGEMENT AND HABITAT: THE CASE OF SPANISH COOPERATION IN THE \\ HISTORIC CENTER OF CUSCO [1999-2010]
}

\author{
CRAYLA ALFARO AUCCA ${ }^{(\star \star)}$ \\ Fecha de recepción: 24 de agosto de 2017 \\ Fecha de aprobación: 18 de noviembre de 2017
}

\begin{abstract}
RESUMEN
Una vez declarado Patrimonio Cultural de la Humanidad por la UNESCO (1983), la atención mundial se centró en el Centro Histórico del Cusco, núcleo de una ciudad con numerosos problemas, especialmente en cuanto a las condiciones de vida inadecuadas de sus habitantes: falta de saneamiento físico y legal, inseguridad, deterioro del tejido social y físico. Ante esta realidad, se realizó el primer esfuerzo para planificar y regular el patrimonio edificado mediante el Plan Maestro del Centro Histórico de Cusco (2005). La participación de la Agencia Española de Cooperación Internacional para el Desarrollo (AECID) entre 1999 y 2010, tanto en la recuperación de viviendas como en la revitalización de ambientes urbanos y el fortalecimiento institucional de la Municipalidad Provincial del Cusco, se convirtió en una de las experiencias contemporáneas de trabajo con mayor cobertura e influencia en la gestión del espacio patrimonial en el Perú. El presente artículo resume el estudio realizado por la autora sobre la experiencia de la AECID en temas de hábitat e institucionalidad, donde se plantea una lectura de cómo esta aportó a la mejora de la calidad de vida de los beneficiarios de los proyectos y cómo estos pueden ser adaptados frente a la problemática actual.
\end{abstract}

\section{PALABRAS CLAVE}

Centro histórico, vivienda y espacio público, cooperación internacional

\begin{abstract}
After it was declared Cultural Heritage of Humanity by UNESCO (1983), the world's attention focused on the Historic Center of Cusco. It is the heart of a city with numerous problems, especially in terms of its inhabitants' inadequate living conditions: lack of sanitation and legal ordering, insecurity, deterioration of its social and physical infrastructure. In light of this reality, an initial effort was made to plan and regulate the city's built heritage through the Master Plan of the Historic Center of Cusco (2005). The participation of the Spanish Agency of International Cooperation for Development (AECID) between 1999 and 2010, both in the recovery of housing as in the revitalization of urban environments and the institutional strengthening of the Provincial Municipality of Cusco, became one of the contemporary work experiences in the management of heritage space in Peru with the greatest coverage and influence. This article summarizes the research carried out by the author on the AECID experience in living and institutional issues. It puts forth a view of how it helped improve the quality of life of the projects' beneficiary participants and how these could be adapted to manage current problems.
\end{abstract}

\section{KEYWORDS}

Historic center, housing and public space, international cooperation

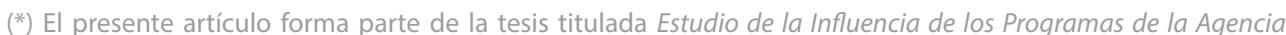
Española de Cooperación Internacional para el Desarrollo en el Ámbito del Centro Histórico de la Ciudad del Cusco, elaborada para optar por el grado de magíster en Gestión del Patrimonio Cultural por la Universidad Mayor de San Marcos (UNMSM) en el 2017.

${ }^{(* *)}$ Arquitecta por la Universidad San Antonio Abad del Cusco, máster en Ciencias Sociales con mención en Gestión del Patrimonio Cultural por la UNMSM. Docente de la cátedra de Historia de la Arquitectura en la Escuela de Arquitectura de la Universidad Andina de Cusco. Fue Gerente del Centro Histórico de Cusco y codirectora de AECID - Cusco. Contacto: craylaa@hotmail.com 
devenir Vol. 5, N9, ENERO - JUNIO 2018, PP. 9-28 - ESTUdIOS I ISSN 2312-7562 | E-ISSN 2616-4949

UNIVERSIDAD NACIONAL DE INGENIERÍA, LIMA

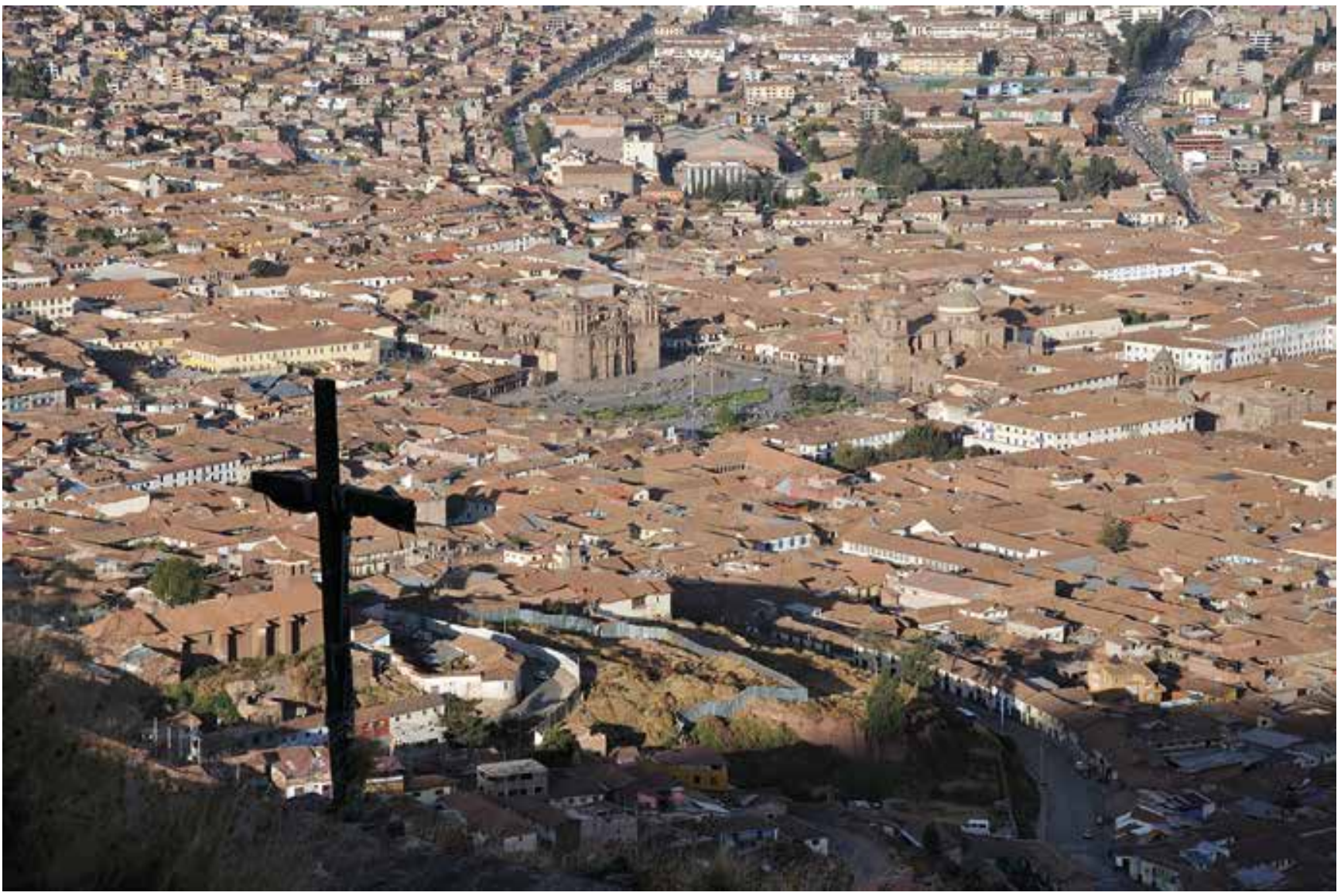

Figura 1. Panorámica del Centro Histórico del Cusco. Archivo fotográfico personal Daniel Castro, 2017
Desde el inicio de la cultura de protección patrimonial, en América Latina se ha desarrollado una tradición de más de 50 años de intervenciones en centros históricos, mediante las cuales se ha obtenido resultados de importancia cualitativa y cuantitativa, lo cual exige tomar un momento para repensar este proceso como experiencia de conocimiento y acción.

Las intervenciones en centros históricos y su patrimonio arquitectónico son ejes fundamentales para afianzar el desarrollo de las ciudades en América Latina durante los próximos decenios, situación que, en términos de la Organización de las Naciones Unidas para la Educación, la Ciencia y la Cultura (UNESCO) y el Consejo Internacional de Monumentos y Sitios (ICOMOS), define la nueva cultura urbana y de la conservación, como la cultura de la recuperación y recualificación de la ciudad existente y del territorio histórico (Gonzales-Varas, 1999).

El punto de partida del presente caso de estudio es el año 1983, cuando el Centro Histórico del Cusco (CHC) fue incluido en la Lista de Patrimonio Mundial de UNESCO, lo que llevó a la priorización de acciones de conservación de los espacios y monumentos que iban siendo registrados, en las que la recuperación del componente vivencial fue incluido de manera progresiva. Desde entonces, esta problemática ha sido enfrentada mediante diferentes estrategias y de forma discontinua.

Una de estas estrategias fue la focalización de presupuesto del Gobierno nacional en la intervención de espacios y edificaciones, desde una visión monumentalista, que considera el turismo como aquella actividad económica que permitiría el desarrollo local. Sin embargo, esta visión distaba de ser integral, pues no consideraba componentes 


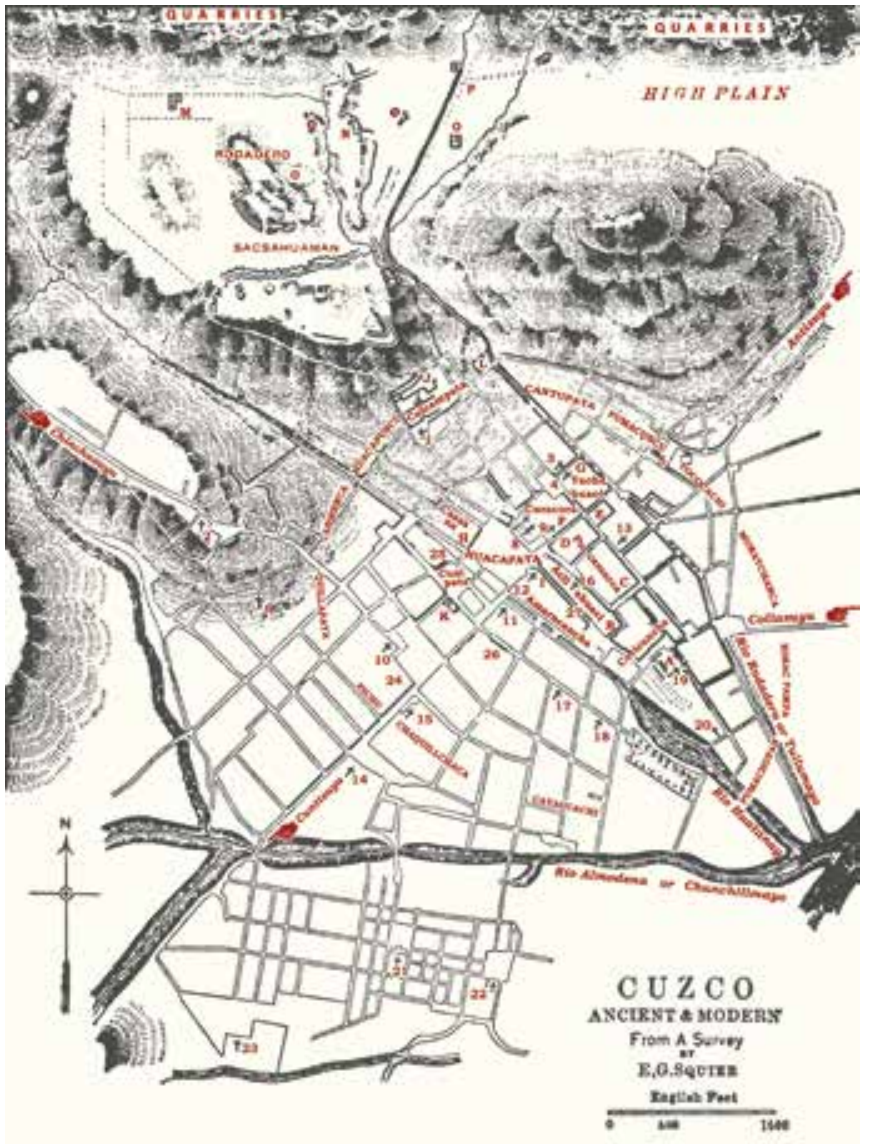

sociales como la vivienda o las actividades que definían los espacios públicos como tales "... daban un mayor énfasis a la restauración de los grandes monumentos con finalidad cultural y/o turística, que propiamente a la rehabilitación urbana del área" (Azevedo de, 2003, p. 13).

Como resultado de ello, se propició un cambio drástico en la estructura urbana, que derivó en la desconfiguración y desnaturalización del espacio tradicional y patrimonial, sumado al subempleo y la incapacidad de generar elementos de desarrollo económico local en la consolidación social y física:

...la conservación de intervenciones monumentalista estuvieron asociadas a una forma de mistificación del pasado y un modo de eludir los problemas sociales de los 'centros'... las áreas centrales fueron vistas más como una suerte de ficción museística pletórica de edificios de gran valor, antes de como un espacio de vida y cultura en permanente cambio. (Harms, Ludeña \& Pfeiffer, 1996, p. 10).

En este contexto, las políticas de la Cooperación Internacional orientadas al desarrollo social en escenarios urbanos con contenido patrimonial y desigualdad socioeconómica permitieron afinar las estrategias de gestión institucional. Tal es el caso de la Agencia Española de Cooperación Internacional para el Desarrollo (AECID), la cual, con un modelo de iniciativa institucional gubernamental compartida (Alfaro, 2017), dio paso hacia la toma de decisiones vinculantes para la gestión del espacio histórico y patrimonial, así como a un escenario idóneo para la reflexión, y el emprendimiento de nuevas estrategias en la búsqueda de soluciones y mejora de la habitabilidad en el CHC (Figura 1).
Figura 2. Mapa del Cusco. Cuzco Ancient \& Modern por E. G. Squier, 1877. Archivo 01 del Centro de Documentación de la Gerencia del Centro Histórico, Municipalidad Provincial del Cusco, 2014.

Figura 3. Crecimiento urbano entre los siglos XVI y XVII. Archivo Diagnóstico del Centro de Documentación de la Gerencia del Centro Histórico, Municipalidad Provincial del Cusco, 2014. 


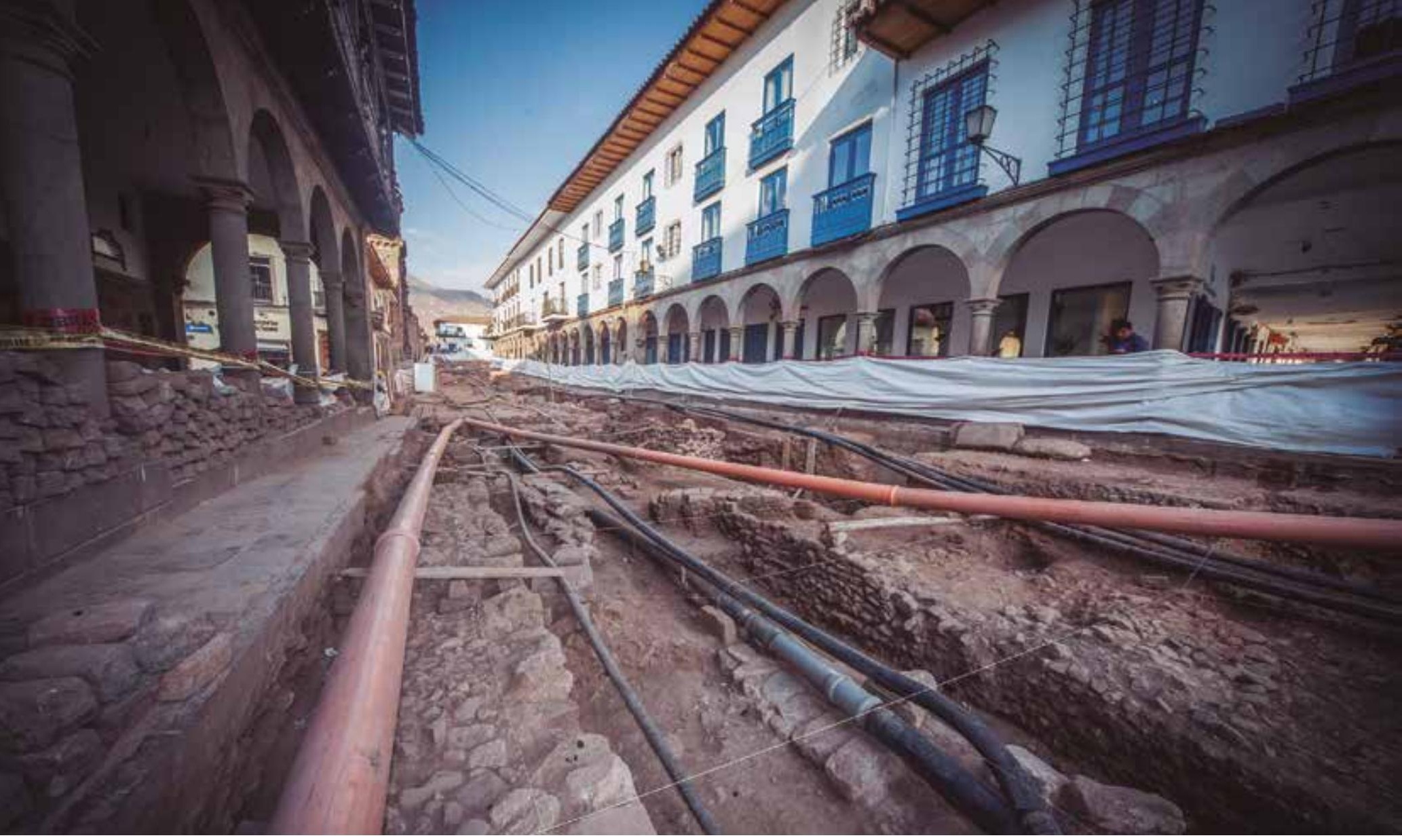

Figura 4. Calle Mantas en 2014. Archivo fotográfico del Centro de Documentación de la Gerencia del Centro Histórico, Municipalidad Provincial de Cusco, 2014.

Figura 5. Delimitación del Centro Histórico de Cusco en el 2005. Archi vo 01 del Centro de Documentación de la Gerencia del Centro Histórico, Municipalidad Provincial del Cusco, 2014

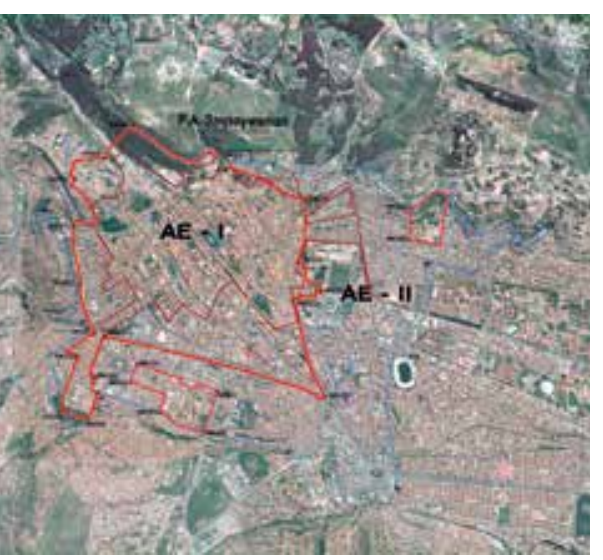

1. World Monument Watch es un programa global que inició sus actividades en 1995, en el marco del 30 aniversario del World Monument Fund, cuyo objetivo es identificar los sitios del patrimonio cultural en peligro, y brindar el apoyo técnico y financiero necesario para su preservación.

2. El Centro Guamán Poma de Ayala es un organismo no gubernamental de desarrollo. Inició sus actividades en Cusco el año 1979, y en el centro histórico de la misma ciudad orientó su trabajo a ordenar la renovación urbana mediante el aumento de la calidad de vida de los ciudadanos, brindando acceso a servicios básicos y ejecutando proyectos de rehabilitación de las viviendas. Además, desde dicho centro se llevaron a cabo acciones enmarcadas en el fortalecimiento de la institucionalidad en la gestión pública, así como en organizaciones sociales. 


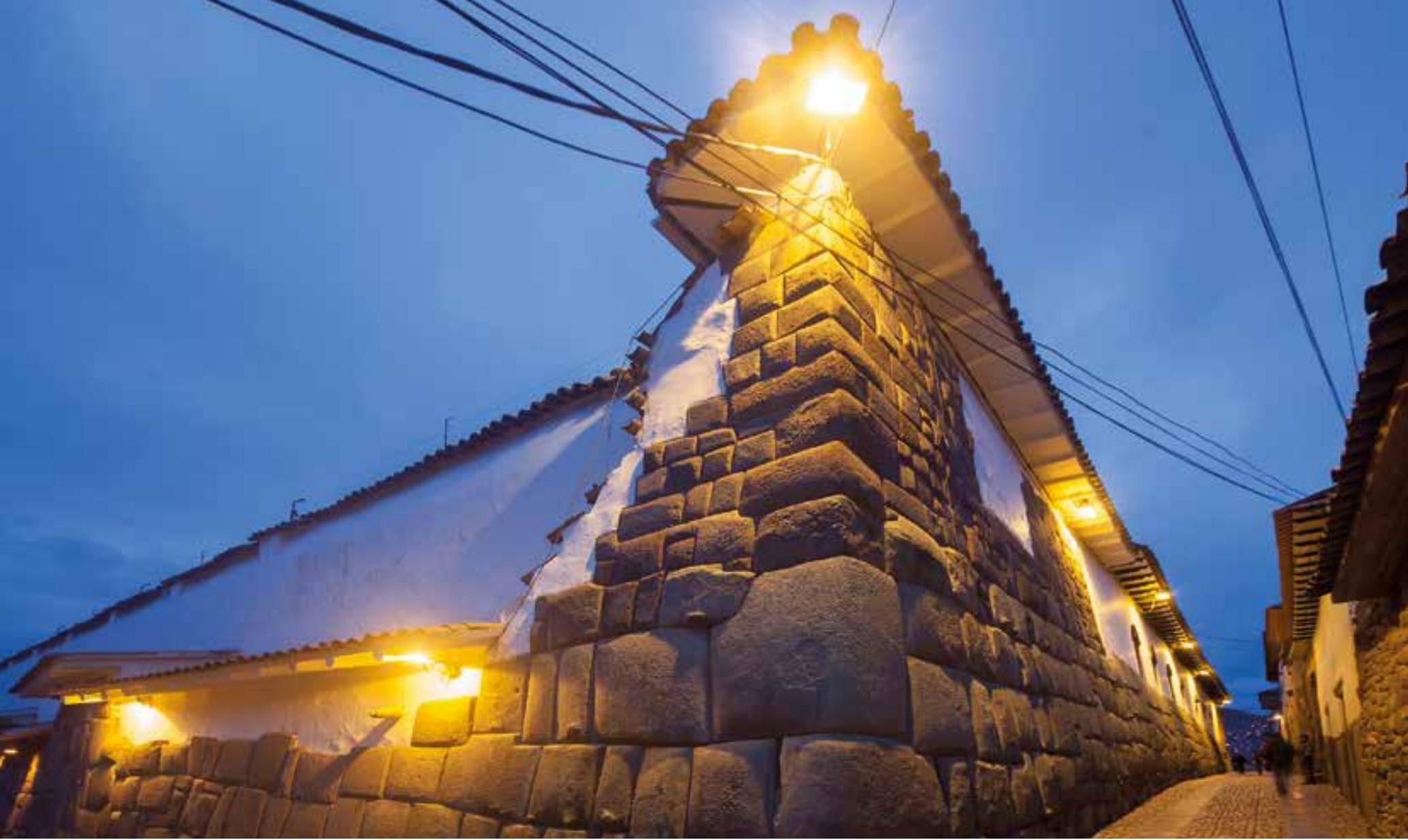

la finalidad de desarrollar proyectos piloto de intervención. Así se formuló el Proyecto Centro Histórico de Cusco, centrado en el estudio de 12 de 108 manzanas existentes.

En 1998, ante la gravedad del deterioro del CHC, la Municipalidad Provincial del Cusco (MPC) solicitó a la Cooperación Española apoyo técnico y económico para revertir esta situación. A partir de ello, en el periodo 1999-2002, se formuló un proyecto de cooperación interinstitucional con el objetivo de dotar a la MPC de las herramientas necesarias para el planeamiento y gestión del CHC, mediante el Plan de Rehabilitación Integral del Centro Histórico del Cusco. En 1999 la MPC, el entonces Instituto Nacional de Cultura-CusCo ${ }^{3}$ (INC) y UNESCO firmaron un contrato de financiamiento de actividades para elaborar el Estado de la Cuestión del Centro Histórico del Cuzco, primer instrumento de gestión territorial para dicha ciudad, participativo y normativo, cuyos lineamientos expresan su voluntad y compromiso por el trabajo conjunto e interinstitucional, y que, eventualmente, se tradujo en el Plan Maestro del Centro Histórico del Cusco, instrumento de gestión orientado a la protección y conservación del patrimonio.

Por su parte, en 2000 el CGPA inicia un proyecto (Figura 6) de intervención en vivienda social que buscó demostrar que

...era posible mejorar la calidad de vida habitacional de pobladores del $\mathrm{CHC}$, conservando las características históricas y arquitectónicas del patrimonio edificado, a través de un modelo de gestión participativo y concertado para la recuperación del centro histórico como espacio vivo y habitable. (Programa Hábitat y Ciudadanía, 2005, p. 17)

3. El Instituto Nacional de Cultura-Cusco, en la actualidad Ministerio de Cultura - Dirección Desconcentrada de Cultura - Cusco, fue creado mediante Ley Nro. 29565 el 21 de julio de 2010 y renovado mediante Decreto Supremo Nro. 001-2010-MC del 01 de octubre del mismo año, cuando el INC se convierte en el Ministerio de Cultura. Esta institución es un eje fundamental del desarrollo sostenible en el Perú: promueve la ciudadanía intercultural, la integración social y la protección del patrimonio cultural de la nación; facilita un mayor acceso a este de parte de la población, así como a los productos culturales y artísticos; y afianza la identidad peruana como visión de creación. La Sub Dirección Desconcentrada de Patrimonio Cultural y Defensa del Patrimonio Cultural es el órgano que contempla las acciones dirigidas al patrimonio edificado en el Centro Histórico del Cusco.

Figura 6. Calle Hatunrumiyoq en 2013. Archivo fotográfico del Centro de Documentación de la Gerencia del Centro Histórico, Municipalidad Provincial del Cusco, 2013 
devenir Vol. 5, Nº9, ENERO - JUNIO 2018, PP. 9-28 - EstudIOS I ISSN 2312-7562 | E-ISSN 2616-4949

UNIVERSIDAD NACIONAL DE INGENIERÍA, LIMA

Figura 7. Plano de condición de hacinamiento. En Diagnóstico de la Actualización del Plan Maestro (Lámina PMCHC FC-V-13). Centro de Documentación de la Gerencia del Centro Histórico, Municipalidad Provincial del Cusco, 2015.

Figura 8. Plano de condición del tipo de vivienda. En Diagnóstico de la Actualización del Plan Maestro ((Lámina PMCHC FC-V-01). Centro de Documentación de la Gerencia del Centro Histórico, Municipalidad Provincial del Cusco, 2015.

\section{AECID, y la estrategia Cultura y Desarrollo}

El trabajo de la AECID comprende acciones en diversos ámbitos, tales como la recuperación de monumentos históricos, la formación de mano de obra calificada para la intervención de monumentos y obras de arte, el mejoramiento de las capacidades para la gestión institucional, y la recuperación de la vivienda y espacios públicos. Todas estas se realizan en ciudades de compromiso patrimonial e histórico, y estaban direccionadas según los lineamientos de su estrategia Cultura y Desarrollo, en beneficio de la población de menores recursos mediante la preservación y el fortalecimiento de sus capacidades culturales, y la preservación de las identidades y la diversidad cultural (Alfaro, 2017).
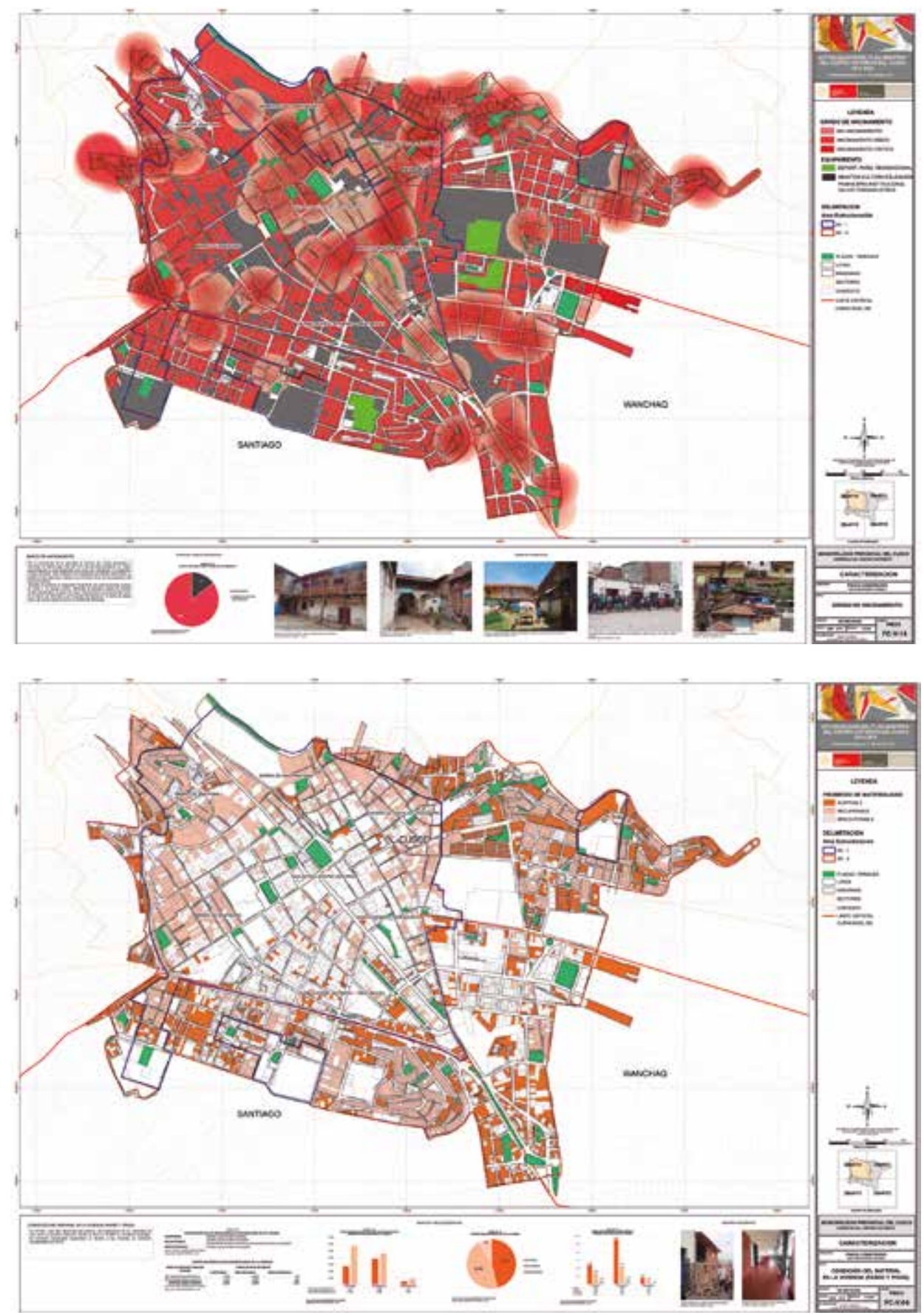
En 1992, la AECID creó la Escuela Taller Cusco, centro educativo que ofrecía formación para jóvenes en oficios tradicionales vinculados a las tareas de conservación del patrimonio cultural del $\mathrm{CHC}$, quienes luego realizarían los trabajos de conservación y restauración en las intervenciones (Programa Patrimonio para el Desarrollo, 2012).

La MPC y la AECID elaboraron en 1999 el Plan de Rehabilitación Integral del Centro Histórico de la Ciudad de Cusco (Plan), donde se prioriza el fortalecimiento institucional, la recuperación y preservación de las viviendas y la revitalización del espacio público. Acorde a este plan se ejecutó seis proyectos en espacios públicos.
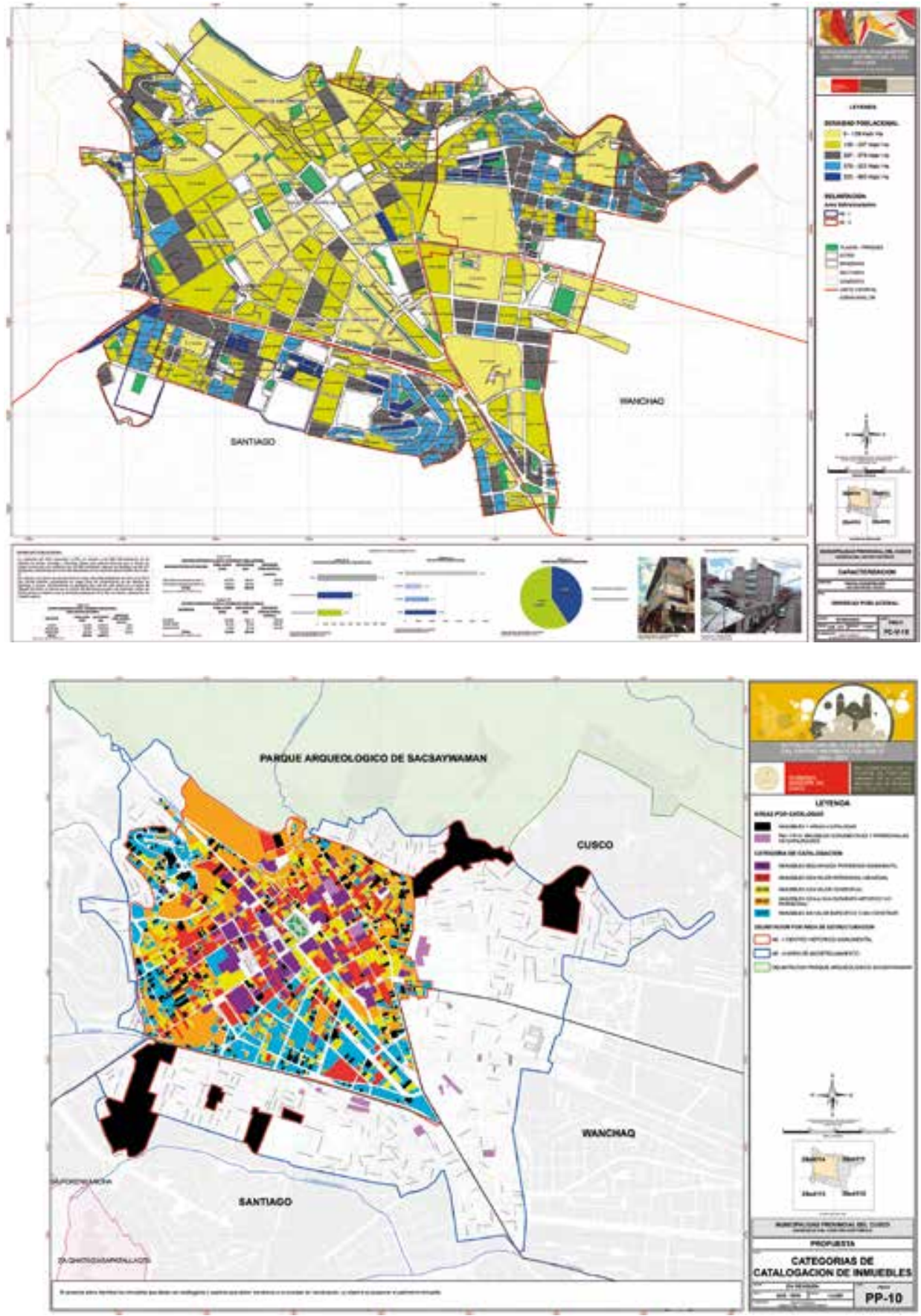

Figura 9. Plano de densidad poblacional. En Diagnóstico de la Actualización del Plan Maestro (Láminas PMCHC FC y PMCHC FC-C-03-18). Centro de Documentación de la Gerencia del Centro Histórico, Municipalidad Provincial del Cusco, 2015.
Figura 10. Plano de catalogación de inmuebles. En Diagnóstico de la Actualización del Plan Maestro (Lámina PMCHC PP-V-10). Centro de Documentación de la Gerencia del Centro Histórico, Municipalidad Provincial de Cusco, 2015 
En el año 2000 se inició la implementación del plan, con la creación de un espacio de coordinación institucional denominado Oficina Técnica del Centro Histórico del Cuzco (OTCHC), adscrita a la MPC: "la cooperación internacional es ya un sujeto patrimonial de escala local, pues conforma el 'complejo institucional' de gobierno de los centros histórico" (Hayakawa, 2015, p. 486).

El año siguiente se firmó el convenio tripartito entre la UNESCO, el INC y la MPC para la elaboración del Plan Maestro del Centro Histórico del Cusco (PMCHC), aprobado en $2005^{4}$, así como su respectiva reglamentación ${ }^{5}$.

En 2003, la OTCHC se integró a la nueva Sub Gerencia de Centro Histórico (SGCH) ${ }^{6}$, la cual fue creada ese mismo año como órgano de línea dependiente de la Gerencia de Desarrollo Urbano y Rural.

Ante la integración de la MPC al Sistema Nacional de Inversión Pública, en 2007, se reformuló el plan maestro para su ejecución entre los años 2007 y 2010, por la SGCH, el cual se integrará a las actividades planteadas en el PMCHC (Alfaro, 2017). En esta etapa se ejecutaron siete proyectos en espacios públicos, así como se intervinieron 19 viviendas mediante tres proyectos.

El año 2011, la SGCH pasó a formar parte de la Gerencia del Centro Histórico (GCH) ${ }^{7}$, la cual recién se implementó en el año 2013, al ser integrada a los instrumentos de gestión operativa de la MPC y su presupuesto institucional. Según Alfaro, "esta incorporación orgánica generó un cambio cualitativo y cuantitativo, perceptible en la gestión del patrimonio edificado en el CHC" (2014, p. 35) (Figuras 7, 8, 9 y 10).

\section{Enfoque metodológico}

La investigación en entornos patrimoniales resulta difícilmente abordable mediante la aplicación de una sola técnica, por lo cual se utilizó una estrategia de triangulación, que implicó emplear una combinación de métodos para el análisis y estudio de los casos. También se aplicó la estrategia de triangulación en el aspecto teórico, de aproximaciones conceptuales y enfoques teóricos, intra e inter metodológica, así como la triangulación de datos de tiempo, espacio y personas.

La recolección de información se llevó a cabo empleando métodos complementarios: encuestas, entrevistas y cuestionarios aplicados a los beneficiarios directos e indirectos, así como a los trabajadores de la AECID y la MPC, con la finalidad de evaluar cuantitativa y cualitativamente la incidencia de esta experiencia para, finalmente, proponer lineamientos que aporten a la construcción de políticas de protección y preservación patrimonial en las instituciones públicas, así como alternativas de solución a las problemáticas del $\mathrm{CHC}$ en cuanto a vivienda y espacio público.

\section{Selección de la muestra}

Para el caso de la problemática en torno a la calidad de la vivienda, se estudiaron 13 de un total de 19 inmuebles que fueron intervenidos en el marco de tres proyectos: "el criterio de selección se basó en la disponibilidad de información primaria, así como el carácter de las intervenciones, pues debían comprometer la recuperación de la habitabilidad de la vivienda y elementos patrimoniales" (Alfaro, 2017, p. 74) (Tablas 1 y 2).

\footnotetext{
4. Aprobado mediante Ordenanza Municipal Nro.115-MC

5. Reglamento del PMCHC aprobado mediante Ordenanza Municipal Nro.140-MC

6. Creada mediante Ordenanza Municipal № 079 - MC

7. Creada por Ordenanza Municipal №39-2012-MPC, modificada con Ordenanza Municipal №34-2013
} 


\begin{tabular}{|c|c|c|c|c|}
\hline Ítem & Proyecto & Año & Tipo de intervención & $\begin{array}{l}\text { Monto de inver- } \\
\text { sión ejecutado }\end{array}$ \\
\hline 1 & Intervención de la calle Tupaq Amaru. & 2004 & $\begin{array}{l}\text { Recuperación del espacio urbano. Calle peato- } \\
\text { nalizada }\end{array}$ & $473,378.68$ \\
\hline 2 & Plazoleta San Pedro & 2004 & $\begin{array}{l}\text { Recuperación de ambiente urbano a la dinámi- } \\
\text { ca social }\end{array}$ & \\
\hline 3 & Calle Santa Clara & 2004 & $\begin{array}{l}\text { Recuperación del espacio urbano. Calle con } \\
\text { preferencia peatonal }\end{array}$ & $283,417.06$ \\
\hline 4 & Plazoleta Comandante Ladislao Espinar & 2005 & $\begin{array}{l}\text { Recuperación del espacio urbano. Calles circun- } \\
\text { dantes peatonalizadas }\end{array}$ & $256,991.06$ \\
\hline 5 & Plazoleta Jesús Lámbarri & 2005 & $\begin{array}{l}\text { Recuperación de ambiente urbano. Calle con } \\
\text { preferencia peatonal }\end{array}$ & $45,411.49$ \\
\hline 6 & Remodelación de pistas y veredas calle Hospital & 2006 & $\begin{array}{l}\text { Recuperación de ambiente urbano. Calle con } \\
\text { preferencia peatonal }\end{array}$ & \\
\hline 7 & $\begin{array}{l}\text { Mejoramiento de la transitabilidad peatonal de la } \\
\text { calle Marqués del Centro Histórico }\end{array}$ & 2007 & $\begin{array}{l}\text { Recuperación de ambiente urbano. Calle pea- } \\
\text { tonalizada }\end{array}$ & $404,563.00$ \\
\hline 8 & Mejoramiento calle Del Medio & 2007 & $\begin{array}{l}\text { Recuperación de ambiente urbano. Calle pea- } \\
\text { tonalizada }\end{array}$ & $113,641.00$ \\
\hline 9 & Mejoramiento de la plazoleta de Almudena & 2007 & Recuperación de ambiente urbano & $932,956.00$ \\
\hline 10 & Mejoramiento de la calle Sunturwasi (Triunfo) del CHC & 2009 & $\begin{array}{l}\text { Recuperación de ambiente urbano. Calle con } \\
\text { preferencia peatonal }\end{array}$ & $929,448.23$ \\
\hline 11 & $\begin{array}{l}\text { Mejoramiento de avisos y señales en el eje procesio- } \\
\text { nal Almudena - San Blas }\end{array}$ & 2009 & Eje señalizado con información etnohistórica & $190,517.37$ \\
\hline 12 & $\begin{array}{l}\text { Mejoramiento del mirador Qosqo Kawarina del barrio } \\
\text { tradicional de San Blas }\end{array}$ & 2011 & $\begin{array}{l}\text { Recuperación de ambiente urbano. Recupera- } \\
\text { ción de espacio urbano mirador }\end{array}$ & $490,897.05$ \\
\hline \multirow[t]{2}{*}{13} & $\begin{array}{l}\text { Mejoramiento de la transitabilidad peatonal de la } \\
\text { calle y plaza Concepción del barrio tradicional de } \\
\text { Santa Ana }\end{array}$ & 2012 & $\begin{array}{l}\text { Recuperación de ambiente urbano. Calle y } \\
\text { parque }\end{array}$ & $714,387.67$ \\
\hline & & & PRESUPUESTO TOTAL S/. & $4^{\prime} 835,608.61$ \\
\hline
\end{tabular}

En cuanto al caso de los espacios públicos, se estudió cuatro de 13 ambientes urbanos intervenidos por el plan:

...las intervenciones en espacios públicos tuvieron carácter integral tanto a nivel de infraestructura, equipamiento, servicios básicos y sensibilización de la población, lo cual permite la selección de una muestra menor que represente adecuadamente las características del conjunto de intervenciones. Además, se seleccionó un caso por barrio tradicional procurando una cobertura representativa a nivel territorial. (Alfaro, 2017, p. 75)

\section{Desarrollo del caso: La recuperación de viviendas}

Las intervenciones realizadas en viviendas se centraron en los barrios tradicionales San Pedro, Santa Ana y San Cristóbal, pues se trata de zonas con mayor cantidad de uso de suelo destinado a vivienda patrimonial, así como con niveles de tugurización y hacinamiento más elevados.

En todos los casos se firmaron convenios tripartitos entre la MPC, la AECID y los propietarios legalmente reconocidos, en los cuales se detallaba las acciones de intervención que se llevarían a cabo, desagregando mano de obra, materiales, maquinaria y gastos generales, así como los cronogramas de ejecución de obra. 
devenir Vol. 5, Nº9, ENERO - JUNIO 2018, PP. 9-28 - EstudIOS I ISSN 2312-7562 | E-ISSN 2616-4949

UNIVERSIDAD NACIONAL DE INGENIERÍA, LIMA

Tabla 2. Relación de proyectos en viviendas intervenidas (2006-2013)

\begin{tabular}{|c|c|c|c|}
\hline Ítem & Beneficiario & Dirección & Presupuesto \\
\hline \multicolumn{4}{|c|}{ Proyecto Puesta en valor de portadas y balcones de la calle San Pedro del CHC } \\
\hline 1 & Casa Cabrera & Calle Hospital N 813 & $33,065.81$ \\
\hline 2 & Casa Herrera & Calle Hospital № 810 & $16,991.84$ \\
\hline 3 & Casa Lovatón & Calle Chaparro $\mathrm{N}^{\circ} 120$ & $65,235.01$ \\
\hline 4 & Casa Montes & $\begin{array}{l}\text { Calle Umanchata } N^{\circ} 106 \text { (domiciliada } \\
\text { en calle Hospital } N^{\circ} 829 \text { ) }\end{array}$ & $16,767.88$ \\
\hline 5 & Casa Pantigoso & Calle Hospital Nº 829 & $13,452.32$ \\
\hline
\end{tabular}

Primera etapa del Proyecto de Mejoramiento de servicios básicos- servicios higiénicos en inmuebles del CHC

\begin{tabular}{|c|c|c|c|}
\hline 6 & Casa Bohórquez & $\begin{array}{l}\text { Calle Chaparro } \mathrm{N}^{\circ} 254 \text {. fracción } 254 \text { - } \\
\text { A2 segundo nivel }\end{array}$ & $14,145.64$ \\
\hline 7 & Casa Estrada Paz & Calle Fierro N 554 & $23,426.31$ \\
\hline 8 & Casa Medina Sánchez & Calle Chaparro N²79-C & $12,423.83$ \\
\hline 9 & Casa Molero & $\begin{array}{l}\text { Calle Chaparro } N^{\circ} 254 \text {. fracción } 254 \text { - } \\
\text { A1 - primer nivel }\end{array}$ & $13,694.24$ \\
\hline 10 & Casa Montes & Calle Umanchata N 106 & $14,822.60$ \\
\hline 11 & Casa Palomino & Calle Qheswa $N^{\circ} 210$ interior C & $13,202.23$ \\
\hline 12 & Casa Pérez Jara & Calle Umanchata $\mathrm{N}^{\circ} 141$ & $12,938.43$ \\
\hline 13 & Casa Surco - Flores & Calle Qheswa N² 236 & $12,483.88$ \\
\hline 14 & Casa Vargas Guzmán & Calle Umanchata $N^{\circ} 241$ & $16,285.51$ \\
\hline 15 & $\begin{array}{l}\text { Casa Yanquirimachi } \\
\text { Zuñiga }\end{array}$ & Calle Umanchata N 277 & $15,246.57$ \\
\hline
\end{tabular}

Segunda etapa del Proyecto de Mejoramiento de servicios básicos- servicios higiénicos en inmuebles del CHC

\begin{tabular}{|c|c|c|c|}
\hline Ítem & Beneficiario & Dirección & Presupuesto \\
\hline 16 & Casa Gamarra & Av. Apurímac $\mathrm{N}^{\circ} 420^{\prime \prime}$ - segundo nivel & $9,134.70$ \\
\hline 17 & Casa Chacón & Av. Apurímac $\mathrm{N}^{\circ} 420^{\prime \prime}-$ primer nivel & $9,640.56$ \\
\hline 18 & Casa Rosas & Calle Hospital N 842 & $9,813.98$ \\
\hline \multirow[t]{2}{*}{19} & Casa Vera & Av. Apurímac $N^{\circ} 431$, fracción $B$ & $9,908.82$ \\
\hline & & PRESUPUESTO TOTAL S/. & $332,680.16$ \\
\hline
\end{tabular}

Elaboración propia sobre la base de información de la Municipalidad Provincial del Cusco-Agencia Española de Cooperación Internacional para el Desarrollo, 2016.

Por su parte, los propietarios debían aportar un promedio del 30\% del total del presupuesto de obra, el cual podían consistir en materiales de construcción y parte de los gastos generales, así como en brindar espacio para el almacenamiento y cuidado de materiales.

La elaboración de los expedientes técnicos, la capacitación a los beneficiarios y el resto del presupuesto -luego del aporte de los beneficiarios y la valorización del aporte de la MPC-, eran asumidos por la AECID. El aporte de la institución contemplaba además la mano de obra calificada, capacitada en la Escuela Taller Cusco, puesto que todos los casos las viviendas contenían elementos de valor patrimonial e histórico, los cuales requerían un tratamiento especializado. La ejecución de las obras y el manejo presupuestal eran centralizados por la AECID. 


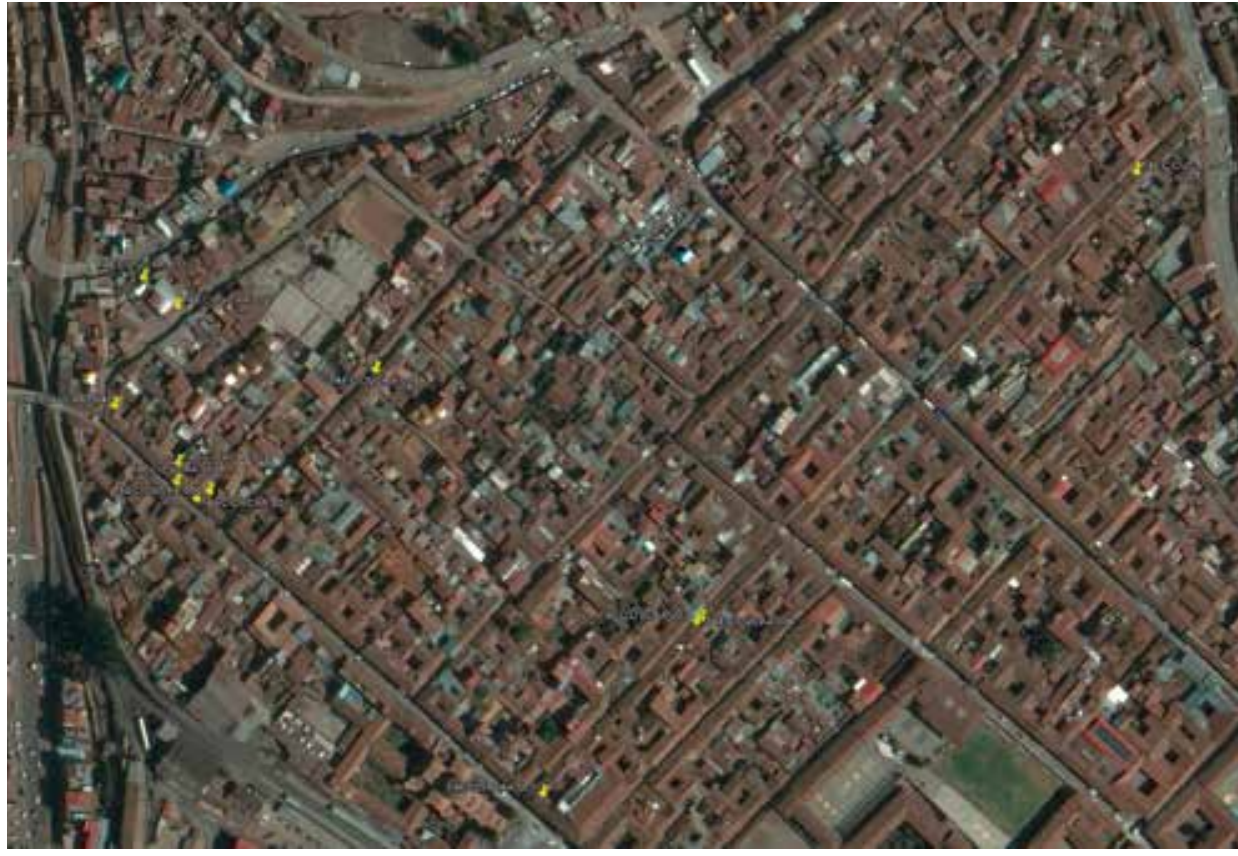

Figura 11. Plano de ubicación de las viviendas seleccionadas. Elaboración propia sobre la base de información de la Municipalidad Provincial del Cusco-Agencia Española de Cooperación Internacional para el Desarrollo, 2016.

El modelo de trabajo consistió en la ejecución de proyectos de forma directa, cada uno mediante un conjunto de intervenciones específicas. Se ejecutaron tres proyectos en el marco del plan:

- Puesta en valor de portadas y balcones de la calle San Pedro del CHC, orientada a la recuperación de estos elementos en cinco inmuebles, intervención que implicó la conservación y restauración a través de la liberación, restitución y pintado de los elementos arquitectónicos.

- Primera etapa del proyecto de mejoramiento de servicios básicos en inmuebles del $\mathrm{CHC}$, que tuvo el objetivo de reubicar los servicios higiénicos y complementarios en emplazamientos adecuados dentro de la infraestructura de las viviendas, cuya ubicación original por lo general había sido resuelta en patios, corredores o zaguanes. Adicionalmente se buscó renovar o mejorar las acometidas de electricidad, agua y desagüe en cuatro de los inmuebles intervenidos.

- Segunda etapa del proyecto de mejoramiento de servicios básicos en inmuebles del $\mathrm{CHC}$, con las mismas características y condicionantes del anterior proyecto. Se analizaron cuatro experiencias de intervención.

Los proyectos fueron elaborados en el marco del entonces Sistema Nacional de Inversión Pública, por lo que fue necesario justificar su pertinencia desde la perspectiva de la seguridad pública. En el caso de los balcones, el estado de deterioro significaba una amenaza constante para los transeúntes de la zona, mientras que, en el caso de las portadas, el deterioro de los portones, sumado a la falta de iluminación y conservación de los zaguanes de ingreso, los habían convertido en escenario de robos y violencia contra los transeúntes.

Esta estrategia solo pudo aplicarse con éxito a los proyectos que afectaban espacios públicos; en aquellos que consistían en intervenciones en el interior de la vivienda, el rol de la MPC se limitó a acciones y aportes desde otros recursos, y actividades indirectas.
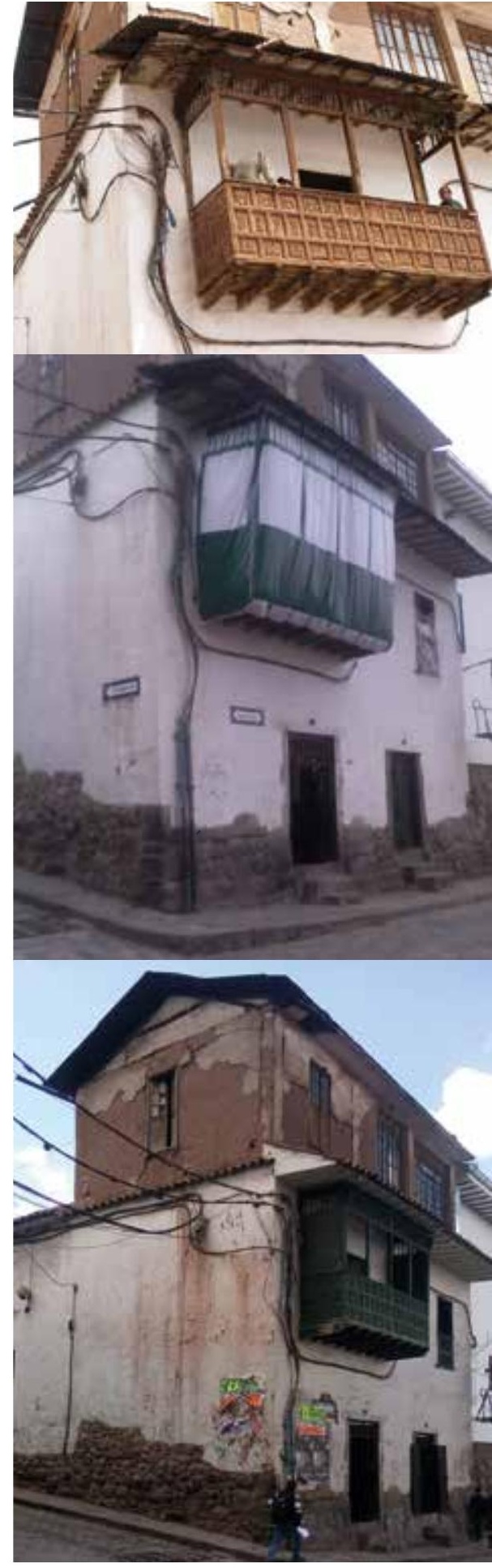

Figura 12. Proceso de recuperación del balcón de la casa Lobatón, 20092014. Sección Intervenciones de la Agencia Española de Cooperación Internacional para el Desarrollo. Centro de Documentación de la Gerencia del Centro Histórico, Municipalidad Provincial del Cusco, 2014. 


\section{Resultados}

- El estudio de incidencia del plan se llevó a cabo en tres proyectos, cada uno de los cuales implicó la realización de una serie de intervenciones en diferentes viviendas. Por lo tanto, la información pertinente se obtuvo a través de entrevistas a 13 personas, de las cuales siete, que representan el $53.85 \%$ de la muestra seleccionada, fueron beneficiarios directos del proyecto en el momento en que fue ejecutado. El resto de entrevistados, que representan el $46.15 \%$ de la muestra seleccionada, fueron beneficiados directamente sin ser titulares de los inmuebles intervenidos, y también estuvieron presentes en el momento de las intervenciones.

- Mediante las entrevistas se obtuvo información respecto de la totalidad de las intervenciones realizadas en dos de los proyectos estudiados. Se consultó por lo menos a una persona sobre cada caso.

- Sobre el tercer proyecto, se obtuvo información de cuatro personas sobre el mismo número de inmuebles, que representan el $40.00 \%$ de un total de 10 intervenciones.

- En total se alcanzó a entrevistar a 13 personas sobre 19 intervenciones, y se obtuvo información respecto del $68.42 \%$ de las intervenciones que conformaron los tres proyectos, de forma que se cumplió con la muestra que se planteó al inicio del estudio.

- Del total de casos, el estudio abarcó la intervención de tres balcones, cinco portadas, ocho zaguanes de ingreso, tres sistemas de red de agua y desagüe, y nueve servicios higiénicos ${ }^{8}$.

- Para la determinación del estado de conservación de las intervenciones, se establecieron seis categorías de evaluación:

a) Excelente: La intervención se encuentra en perfectas condiciones de operatividad y ha recibido mantenimiento periódico.

b) Bueno: La intervención se encuentra en buenas condiciones y, aunque solo ha recibido mantenimiento esporádico, sigue cumpliendo con sus funciones.

c) Regular: La intervención cumple con sus funciones, aunque la falta de mantenimiento se hace evidente a simple vista.

d) Malo: Debido al uso y la falta de mantenimiento, la intervención cumple con dificultad sus funciones y requiere de mantenimiento inmediato para seguir operando.

e) Deficiente: La intervención no se encuentra en condiciones de cumplir sus funciones debido a la falta de mantenimiento.

f) Inexistente: La intervención ha sido desmantelada o sustituida.

Bajo estos parámetros, se identificó que el $30.77 \%$ de las intervenciones se encontraban en buen estado; el 61.54\%, en estado regular; $y$ el 7.69\%, en mal estado.

- Se encontró también que, de un total de 13 intervenciones, el 100\% mantiene el uso para el cual fue ejecutada.

- Finalmente, se observó que si bien al inicio del proyecto se atendió a 36 familias beneficiarias ${ }^{9}$, en la actualidad son 67 las familias que se benefician de las intervenciones, lo que indica que hubo un crecimiento considerable del número de habitantes (86.11\%) desde el momento de las intervenciones hasta la fecha del estudio.

8. Las intervenciones de servicios higiénicos contemplaban la dotación de lavatorios, duchas e inodoros; el acceso a agua potable; y la conexión a redes de desagüe.

9. Información que se obtuvo de las placas de entrega de obra y los archivos de los proyectos. 


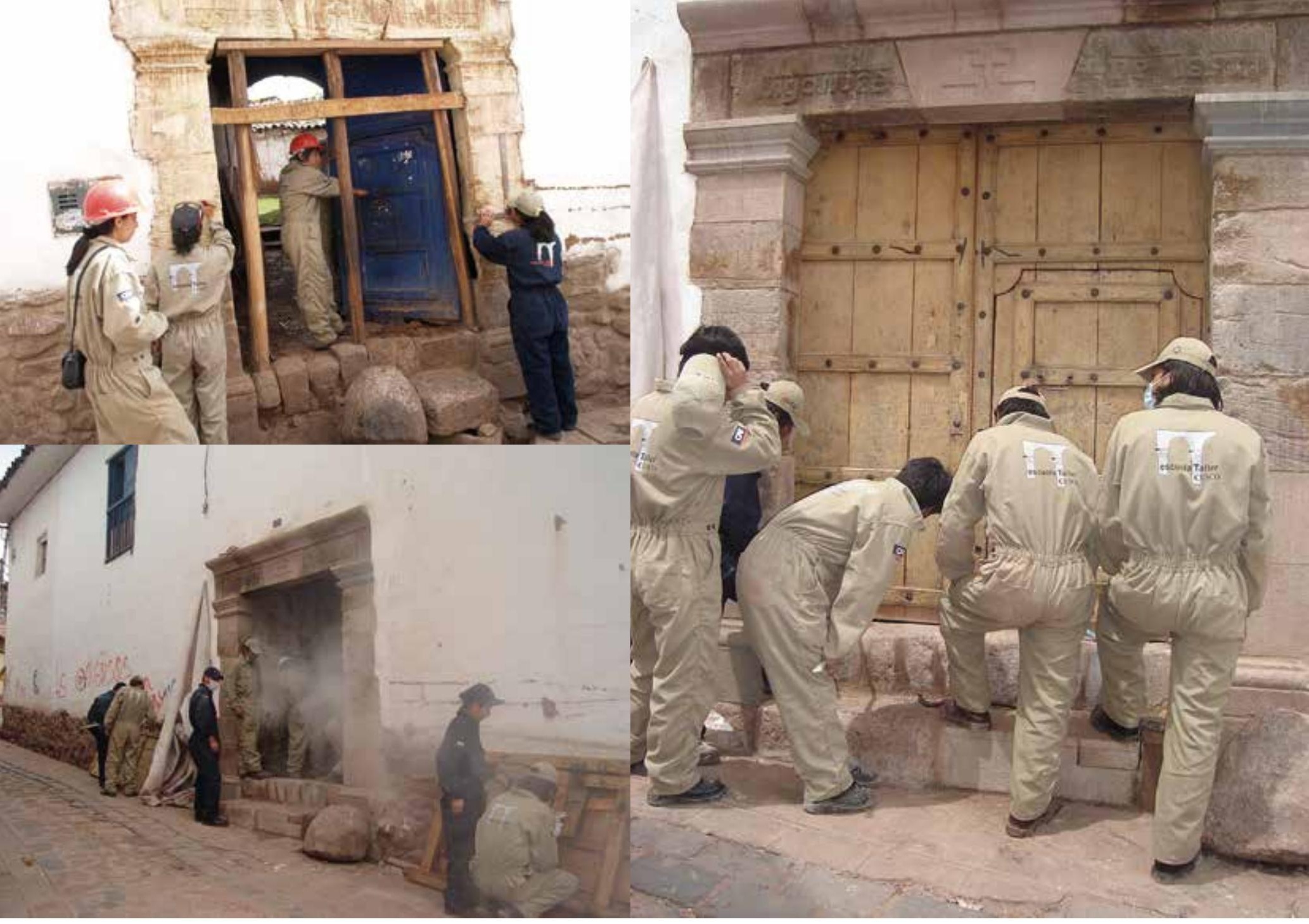

\begin{tabular}{cccc} 
Tabla 3. Relación de viviendas seleccionadas para el estudio & $\begin{array}{c}\text { Número de familias benefi- } \\
\text { Cítem }\end{array}$ & $\begin{array}{c}\text { Intervención en momento de la } \\
\text { intervención }\end{array}$ & $\begin{array}{c}\text { Numilias benefi- } \\
\text { ciarias en la actualidad }\end{array}$ \\
\hline 1 & Casa Cabrera & 4 & 13 \\
2 & Casa Herrera & 1 & 3 \\
3 & Casa Lovatón & 1 & 3 \\
4 & Casa Montes & 1 & 1 \\
5 & Casa Pantigoso & 1 & 3 \\
6 & Casa Molero & 2 & 5 \\
7 & Casa Bohórquez & 1 & 1 \\
8 & Casa Estrada Paz & 8 & 10 \\
9 & Casa Palomino & 8 & 10 \\
10 & Casa Rosas & 6 & 12 \\
11 & Casa Gamarra & 1 & 2 \\
12 & Casa Chacón & 1 & 3 \\
13 & Casa Vera & 1 & 1 \\
\hline & TOTAL & $\mathbf{3 6}$ & $\mathbf{6 7}$ \\
\hline
\end{tabular}

Figura 13. Proceso de recuperación de la portada de la casa Montes. Gerencia de Centro Histórico, 20092014. Sección Intervenciones de la Agencia Española de Cooperación Internacional para el Desarrollo. Centro de Documentación de la Gerencia del Centro Histórico, Municipalidad Provincial del Cusco, 2014.

Elaboración propia sobre la base de información de la Municipalidad Provincial del Cusco-Agencia Española de Cooperación Internacional para el Desarrollo, 2016. 


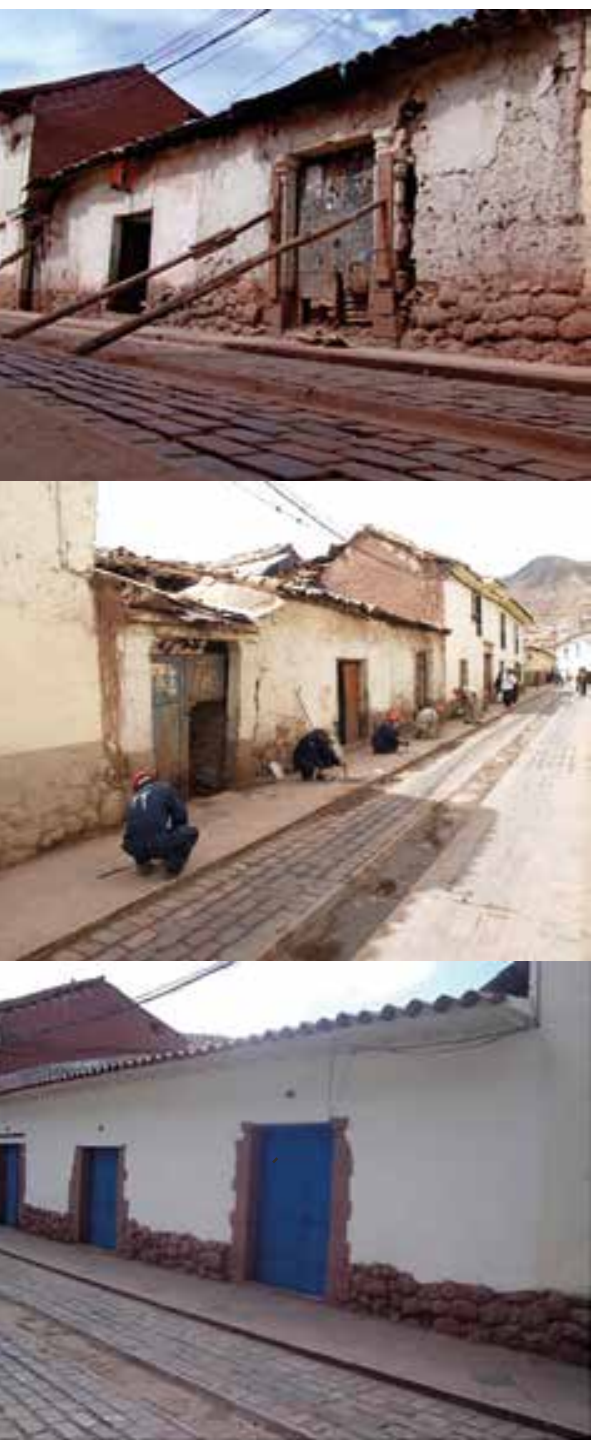

Figura 14. Proceso de intervención para dotación de servicio básicos y rehabilitación de la casa Cabrera, 2009-2014. Sección Intervenciones de la Agencia Española de Cooperación Internacional para el Desarrollo. Centro de Documentación de la Gerencia del Centro Histórico, Municipalidad Provincial del Cusco, 2014.
- En nueve de las 13 viviendas estudiadas, que representan el $69.23 \%$ de la totalidad (con excepción de las casas Pantigoso, Vera, Gamarra y Bohórquez), los propietarios han destinado ambientes a otras actividades, generándolo cual ha generado un cambio a usos mixtos, como vivienda-comercio, vivienda-hospedaje y vivienda-taller.

- En los casos en los que los propietarios implementaron ambientes para usos complementarios y alquiler, las subdivisiones se han llevado a cabo en condiciones precarias y ocupan parcialmente los patios centrales (Figuras 11, 12, 13, 14 y Tabla 3).

\section{Debate}

- El estado de conservación en que se encuentran las intervenciones en la actualidad varía entre regular y bueno, situación que afirma la utilidad de estas para sus habitantes. Sin embargo, se observa también que en algunos casos han recibido menos atención de la que ameritaría por ser espacios de uso común de numerosas familias, debido a que el $46.15 \%$ de los usuarios habita en condición de residente temporal y no llega a desarrollar un empoderamiento respecto del espacio.

- Las intervenciones realizadas en los zaguanes de acceso han recibido mayor mantenimiento, sobre todo en los casos en que se desarrollaron actividades comerciales y de hospedaje, que abarcan el $61.54 \%$ de las intervenciones.

- Otro factor que influye en la falta de mantenimiento es el cultural, pues las familias no tienen la costumbre de reservar presupuesto para trabajos de mantenimiento, y solo actúan ante incidentes eventuales, como averías que condicionan la normalidad del servicio.

- El incremento del turismo en el $\mathrm{CHC}$ ha determinado la implementación de actividades comerciales y de hospedaje en los inmuebles, sin que ello implique el desplazamiento de los usos de vivienda.

- Ha tenido lugar un proceso de subdivisión progresiva, debido a que los herederos de los propietarios beneficiados siguen ocupando los inmuebles. Como se indicó previamente, desde que se realizaron las intervenciones, el número de beneficiarios se ha incrementado en $86.11 \%$.

- Sin embargo, a pesar del incremento en la cantidad de habitantes, no se ha incrementado la capacidad de los servicios que los atienden.

\section{La recuperación del espacio público}

Inicialmente, el criterio empleado para determinar la ubicación de los proyectos fue el cumplir con el objetivo de focalizar acciones en el llamado eje procesional, un elemento ordenador urbano que ha trascendido a lo largo de la historia de la ciudad, y el alto valor patrimonial y arqueológico ubicado en su subsuelo. Posteriormente, en coordinación con la MPC, se llevó a cabo otro conjunto de acciones, esta vez fuera del eje procesional, por el impacto social que se esperaba generar.

En ambos casos, las intervenciones estaban orientadas a favorecer el ordenamiento del espacio público a través de la erradicación del comercio ambulatorio, así como a procurar condiciones de seguridad pública. Además, los proyectos se orientaron a la peatonalización como principio de movilidad urbana idóneo en ciudades históricas, situación que permitiría el goce del espacio mediante la restricción del tránsito vehicular, en unos casos y, en otros, mediante la peatonalización completa.

Finalmente, en los proyectos tardíos, fuera del eje procesional, se intentó recuperar espacios públicos que, por falta de mantenimiento, se habían desarticulado de la dinámica social y habían quedado abandonados, de modo que se convirtieron en lugares peligrosos (Tabla 4). 


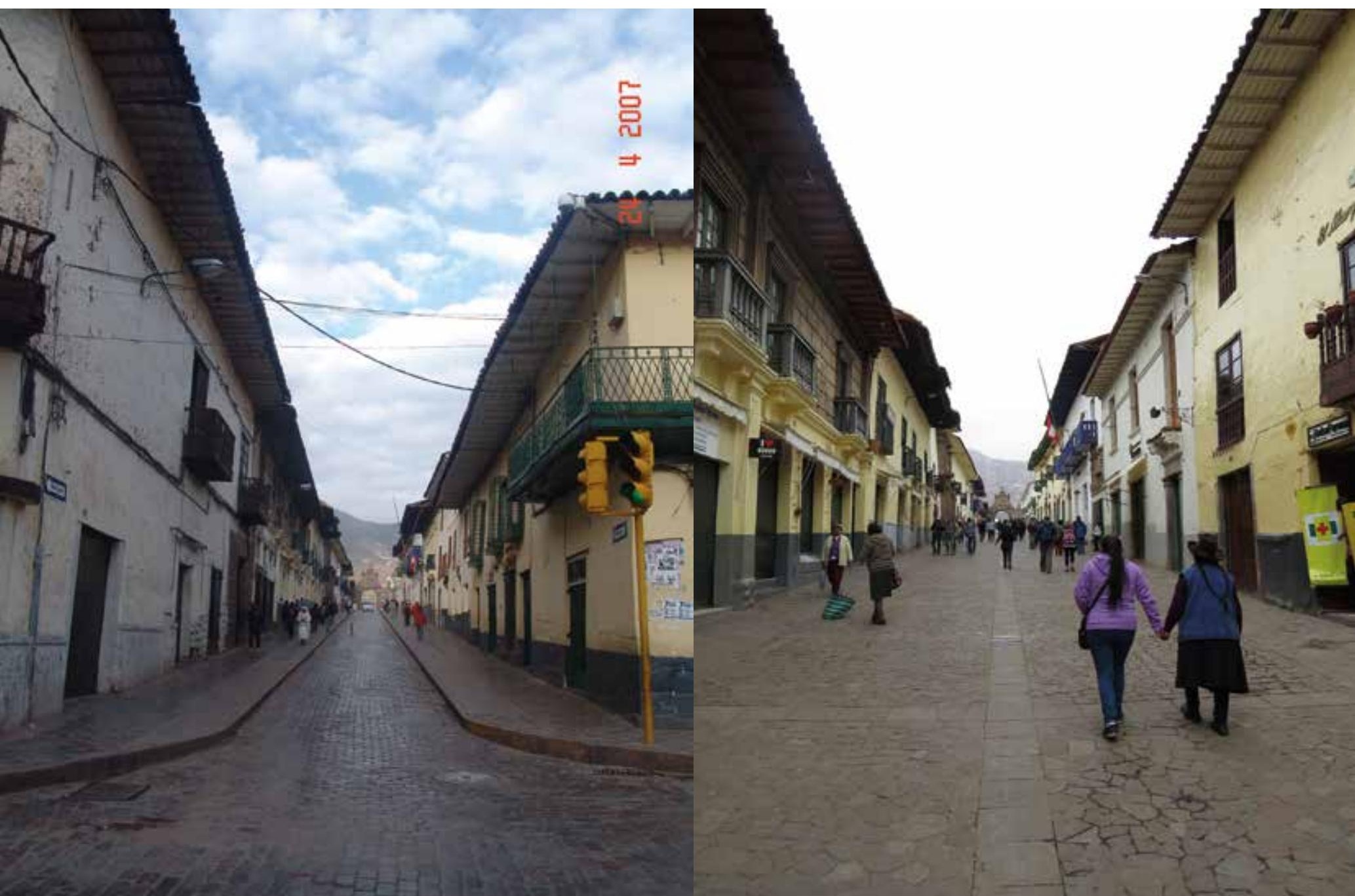

Tabla 4. Evaluación de ambientes urbanos. Mantenimiento de los elementos del ambiente urbano

\begin{tabular}{ccc} 
Ítem & Proyecto & Calificación \\
\hline 1 & Mejoramiento de la transitabilidad peatonal de la calle Marqués & 2.6 \\
2 & Mejoramiento de la calle Sunturwasi (Triunfo) & 2.29 \\
3 & $\begin{array}{r}\text { Mejoramiento del mirador Qosqo Kawarina del barrio tradicional } \\
\text { de San Blas }\end{array}$ & 2.57 \\
4 & $\begin{array}{r}\text { Mejoramiento de la transitabilidad peatonal de la calle y plaza } \\
\text { Concepción del barrio tradicional de Santa Ana }\end{array}$ & 2.14 \\
\hline
\end{tabular}

Elaboración propia sobre la base de información de la Municipalidad Provincial del Cusco-Agencia Española de Cooperación Internacional para el Desarrollo, 2016.
Figura 15. Intervención en la Calle Márquez. Archivo Diagnóstico de Centro de Documentación de la Gerencia del Centro Histórico, Municipalidad Provincial del Cusco, 2015. 
devenir Vol. 5, N9, ENERO - JUNIO 2018, PP. 9-28 - ESTUdIOS I ISSN 2312-7562 | E-ISSN 2616-4949

UNIVERSIDAD NACIONAL DE INGENIERÍA, LIMA

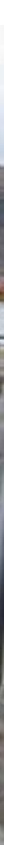

Figura 16. Revitalización del Mirador QosqoKawarina (2009-2010). Sección Intervenciones de la Agencia Española de Cooperación Internacional para el Desarrollo. Centro de Documentación de la Gerencia del Centro Histórico, Municipalidad Provincial del Cusco, 2014.

\section{Los resultados}

Tras el levantamiento de información mediante cuatro fichas de evaluación y 12 entrevistas en campo, se obtuvo la siguiente información:

- El 100\% de los ambientes mantiene sus usos originales.

- Se estableció una escala de calificación del estado de conservación de acuerdo al estado de mantenimiento de los elementos conformantes del ambiente, que consta de un rango de 00 a 05, donde el valor menor representa el estado ruinoso e inservible de la intervención, y el valor mayor que este se encontraba en perfectas condiciones.

- Se observó que ninguno de los proyectos comprendió la implementación de mobiliario urbano como basureros o peones, que tres de los cuatro proyectos contemplaron cámaras de video vigilancia y que solo un proyecto contempló la implementación de un espacio específico para comercio.

\section{Debate}

Los cuatro ambientes estudiados han mantenido el uso que fue planteado a partir de las intervenciones. Las características particulares de cada caso determinan los motivos de esta continuidad:

- En la calle Marqués, la intervención ha permitido el uso peatonal, lo cual ha dinamizado las actividades comerciales formales e informales.

- En la calle Sunturwasi, la intervención permitió la restricción del acceso a vehículos pesados, de forma que se favoreció la circulación peatonal, lo cual dinamizó la actividad comercial formal.

- En el mirador Qosqo Kawarina, ha tenido lugar una renovación del ambiente y su entorno, que cuenta con valor agregado gracias a la disposición de información etnohistórica como parte del mobiliario. Sin embargo, la intención de integrar actividades comerciales particulares no ha tenido una respuesta adecuada debido a conflictos entre los vecinos (limitaciones para la organización y el consenso). 


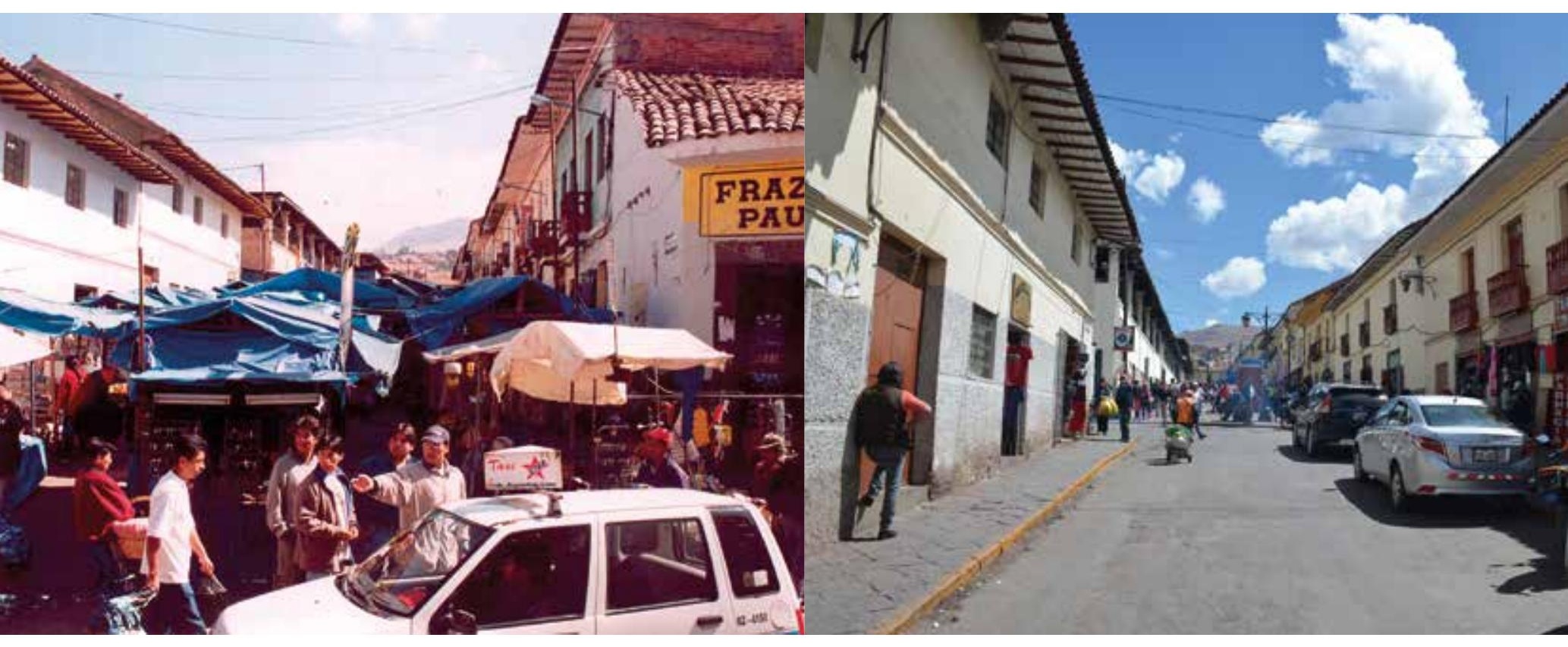

- En la calle y plaza Concepción, aunque se ha recuperado el ambiente, la falta de mantenimiento periódico está degradando nuevamente el espacio y sus elementos.

- La falta de mantenimiento y las condicionantes culturales de los usuarios han determinado la lamentable situación del estado del mobiliario de los ambientes urbanos intervenidos, que en la escala de calificación propuesta alcanzan un promedio de 2.16, que representa que los elementos se encuentran deteriorados y requieren mantenimiento inmediato para seguir prestando servicios (Figuras 15, 16, 17 y 18).

\section{Lecciones y aportes}

La recuperación de zonas degradas en sectores de compromiso patrimonial es una necesidad estructural para el mejoramiento de la calidad de vida de sus habitantes, la recuperación del patrimonio edificado y la preservación del patrimonio cultural inmaterial. Para realizar dichas tareas, urge la necesidad de que se establezca lineamientos sectoriales que, desde los niveles más altos de decisión en la inversión pública, consideren la importancia del patrimonio cultural material e inmaterial en la construcción social.

La rehabilitación como modelo de intervención puede constituirse en garantía para conseguir un desarrollo sostenible, pues no solo involucra aspectos físicos, sino el desarrollo de las economías locales y la preservación del patrimonio cultural inmaterial.

Las intervenciones aquí analizadas muestran que es necesario desarrollar una relación de empatía e identificación entre los sujetos y el espacio que habitan, lo cual puede lograrse a través de la capacitación y sensibilización progresiva, así como mediante su participación económica, la cual contribuye a darle un carácter tangible a la mejora desde la perspectiva de los beneficiarios. Este es un factor estratégico en la conservación mediata de los centros históricos, pero sobre todo en la recuperación sostenible del espacio patrimonial. Del mismo modo, el desarrollar empatía y empoderamiento de los habitantes en relación a los espacios públicos intervenidos, resulta estratégico para dar sostenibilidad a dichas intervenciones.
Figura 17. Renovación urbana en la Calle Tupaq Amaru (2003-2005). Sección Intervenciones de la Agencia Española de Cooperación Internacional para el Desarrollo. Centro de Documentación de la Gerencia del Centro Histórico, Municipalidad Provincial del Cusco, 2014 


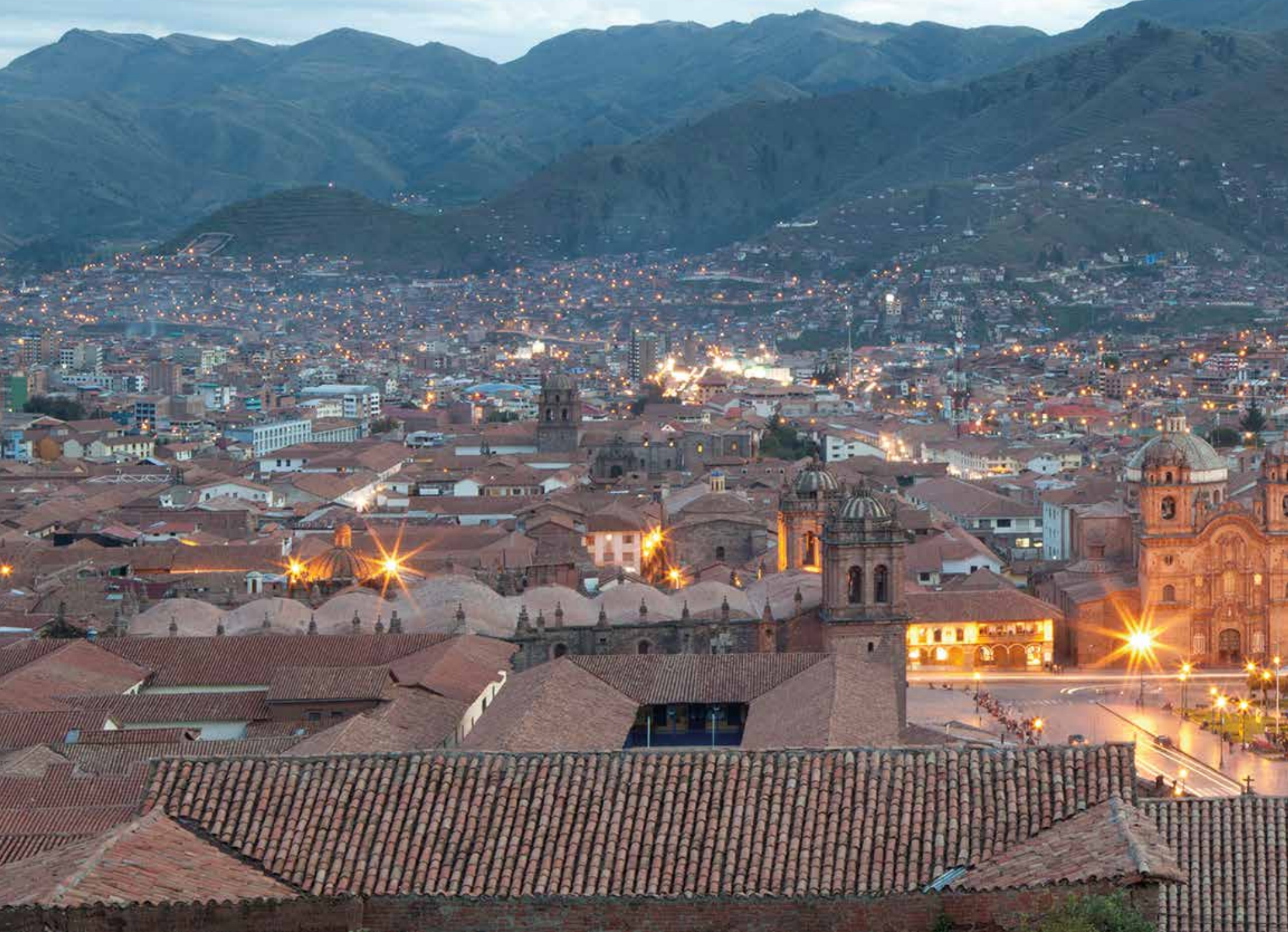

Un factor determinante en la calidad de las intervenciones ha sido el nivel de especialización de los profesionales que ejecutaron los proyectos, sobre todo en casos como este, vinculados a la recuperación patrimonial e histórica.

A pesar de sus limitaciones, las intervenciones realizadas en viviendas sirvieron para mejorar las condiciones de habitabilidad; y solucionaron carencias elementales como la evacuación de aguas servidas, el abastecimiento de agua potable, el ordenamiento del cableado eléctrico, la implementación de servicios higiénicos y liberación de espacios uso común dentro de los inmuebles, factores de mejoramiento de la salud pública. La carencia de estos servicios o su precariedad había convertido a las viviendas en una amenaza para sus residentes, situación que ha sido revertida, como puede verificarse en la actualidad.

En cuanto a los cambios generados en la percepción de la población beneficiada por las intervenciones frente a la problemática del patrimonio y el hábitat en el ámbito del $\mathrm{CHC}$, el estudio reafirma el principio de que la vivienda dota de carácter a la ciudad patrimonial, y la atención de sus múltiples problemas demanda soluciones diseñadas para su realidad específica, por lo que es necesario diseñar programas focalizados, subvencionados por programas del Estado, que deben estar integrados en políticas nacionales de superación de la pobreza y mejoramiento de la calidad de vida. 

Urge la necesidad de generar recursos que procuren operatividad institucional en términos de gestión y control de la ciudad patrimonial, pues si bien existe una gran cantidad de información y se ha ensayado alternativas de solución, la falta de presupuesto de aplicación específica en centros históricos (declarados por UNESCO y reconocidos por el Estado peruano) posterga la atención de los problemas y descontextualiza las soluciones planteadas.

Finalmente, el estudio permite inferir que es posible concertar la conservación del patrimonio edificado y el mejoramiento de las condiciones de habitabilidad de la población residente. Sin embargo, a pesar de los beneficios y aciertos de los proyectos analizados, el estudio también demostró que, al terminar los trabajos realizados por la $A E C I D$, no se encontró el espacio ni las condiciones para que el proyecto pudiese ser replicado. Ello se debe probablemente a que, como proceso económico, la intervención en centros históricos no es compatible con el modelo planteado para el financiamiento de vivienda desde el Estado, pues sus programas no están diseñados para afrontar la realidad de la vivienda tradicional de carácter patrimonial: por lo general, propietarios y residentes no cumplen los requisitos que las instituciones financieras requieren para otorgar financiamiento; $y$, finalmente, porque el nivel de detalle y la complejidad del trabajo termina reduciendo las utilidades para potenciales inversionistas.

\section{Referencias}

Alfaro, C. (2014). Cusco: Identidad y desarrollo. En Cusco: Identidad y desarrollo (pp. 12-35). Cusco, Perú: Municipalidad del Cusco.

Alfaro, C. (2017). Estudio de la influencia de los programas de la Agencia Española de Cooperación Internacional para el Desarrollo en el ámbito del Centro Histórico de la ciudad del Cusco, Perú. Cusco, Perú: Municipalidad de Cusco.

Alfaro, C., Beltrán-Caballero, A. \& Mar, R. (2014). Urbanismo inka del Cusco: Nuevas aportaciones. Cusco, Perú: Municipalidad del Cusco.

Azevedo de, P. (2003). Proyecto Gestión Integral del Patrimonio Cultural. La Habana, Cuba: Organización de las Naciones Unidas para la Educación, la Ciencia y la Cultura.

De La Calle, M. (2002). La ciudad histórica como destino turístico. Barcelona, España: Ariel.

Gonzales-Varas, I. (1999). Conservación de bienes culturales. Teoría, historia, principios y normas. Madrid, España: Cátedra.

Harms, H., Ludeña, W. \& Pfeiffer, P. (1996). Vivir en el "Centro": Viviendas e inquilinato en metrópolis latinoamericanas. Hamburgo, Alemania: Technische Universität Hamburg.

Hayakawa, J. (2015). Gestión del patrimonio cultural y centros históricos latinoamericanos: Tendiendo puentes entre el patrimonio y la ciudad (2da ed.). Lima, Perú: Universidad Nacional de Ingeniería.

Municipalidad Provincial del Cusco (2015). Actualización del Plan Maestro del Centro Histórico de Cusco. Cusco, Perú: Gerencia del Centro Histórico.

Programa Hábitat y Ciudadanía. (2005). Rehabilitación de vivienda patrimonial y social: Centro Histórico de Cusco. Cusco, Perú: Centro Guamán Poma de Ayala.

Programa Patrimonio Para El Desarrollo. (2012). PROYECTOS PERU. P>D Programa Patrimonio para el Desarrollo 1990-2011. Lima, Perú: Agencia Española de Cooperación Internacional para el Desarrollo. 